\title{
South Asian Women Elders and Everyday Lives of 'Care in the Community' in Britain: The Neoliberal Turn in Social Care and the Myth of the Family
}

Navtej Purewal (SOAS University of London)

Rubina Jasani (University of Manchester)

\begin{abstract}
This article focuses upon the myth of the South Asian family as a self-fulfilling unit in which a construction of 'looking after their own' in the diaspora is perpetuated which intrinsically assumes how care and caring are organised at home. The Care in the Community agenda in Britain, which comes out of the contemporary neoliberal paradigm of austerity in which social welfare services have been dramatically cut and reformulated, utilises this imagined myth of the South Asian family in its judgments of the needs of South Asian women elders. Based on fieldwork at a South Asian women's centre in Britain, the article highlights how women's senses of self and selflessness relate to and reflect the neoliberal decline of welfare in which 'looking after their own' presents an ideal for policies which are rescinding delivery of services and entitlements. We highlight how South Asian women elders are absorbing the burdens of this social care paradigm shift while also bearing the strains of generational shifts around the culture of the family and expectations of women's roles as they move through the life course as carers and as those being cared for.
\end{abstract}

Keywords: ageing, care in the community, gender, neoliberalism, South Asia diaspora, social care

Word count: 8972 
This is the version of the article accepted for publication in South Asian Diaspora published by Taylor \& Francis online on 16 June 2016 available at: http://dx.doi.org/10.1080/19438192.2017.1339381

Accepted version downloaded from SOAS Research Online: http://eprints.soas.ac.uk/24283/

\section{South Asian Women Elders and Everyday Lives of 'Care in the Community' in Britain: The Neoliberal Turn in Social Care and the Myth of the Family}

\section{Introduction}

The minibus which bears the name of the South Asian Women's Centre (hereafter called The Centre) can be seen on weekday mornings circling this urban locality of South Asian concentration in the British West Midlands region. The minibus picks up older South Asian women from their homes and takes them to basic English and IT classes, drop-in sessions, and a regular Friday luncheon club. The scene deceptively resonates with images from Gurinder Chadha's 1993 film Bhaji on the Beach which became a cliché for perceived tensions and contestations across younger and older generations of South Asian women in Britain. Our study aims to take the lens away from such culturalist portrayals of generation, community and South Asian culture in order to develop a more nuanced understanding of how older South Asian women articulate their needs within their locations of kinship and community in the context of the family, services for elders, and care needs.

The South Asian women in this study were part of the wave of 'economic migrants' who had moved to the Britain between the 1950s and 1980s from different regions in India, Pakistan, Bangladesh and East Africa. While most of them were housewives, some had worked in factories and one of them had formal education and was a school teacher. Most of the women in the group were widows within the age group of 55 to 80 . Our intention was to explore how conceptions of the South Asian family inflect the ways in which social care and needs are understood in relation to these women in two realms. The first is how older South Asian women are viewed by both their families and agencies as not only being the apex of the family unit but also embodying it, creating a hollowed position for them in terms of addressing their needs. The second is that these women's social worlds are constituted by a normative moral framework of kinship and family, in which the predominant patriarchal family unit's lifecycle places them in a seeming position of power [i.e. women gain status and power as they grow older] through what Ranajit Guha (1987) calls a 'rounded unitary world of kinship.' This is the site of immense challenge, change and critique for these women, all of whom have migrated at least once to settle in the UK. This world of kinship consists of evolving relations with siblings, husbands, daughters, sons, daughters-in-law, and grandchildren with whom boundaries of the family are continually being negotiated in terms of obligations and expectations. An added dimension to this equation is the relationship with the state either to negotiate issues of physical health and mental health with the National Health Service (NHS), pensions, benefits from social services, and bus passes or transport to community centres for recreation.

The perception that older men and women wield 'respect' in the South Asian kinship system and, more significantly, are cared for by immediate kin forms the conceptual basis of how the South Asian family is understood by mainstream society and, as we will highlight here, institutions. Further, caring in the South Asian family unit is a gendered activity, and 'the family' exists as a unit of individuals with emotional attachment as well as a collective unit of actors with moral, economic, and social obligations to care and be cared for, which are inscribed in the notion of the family across the life-course. The South Asian family has been widely 
This is the version of the article accepted for publication in South Asian Diaspora published by Taylor \& Francis online on 16 June 2016 available at: http://dx.doi.org/10.1080/19438192.2017.1339381

Accepted version downloaded from SOAS Research Online: http://eprints.soas.ac.uk/24283/

portrayed as a self-fulfilling unit which public agencies, including health, social welfare, and social services, have utilised in depicting the cultural context of the family unit as 'looking after their own' (Katbamna et al 2004). Popular conceptions of ethnicity and culture, built upon such stereotypes, have significant impacts upon how services are allocated and delivered. In the context of cuts to public services and entitlements for older people in Britain, many care services have become difficult to access or claim for older people, largely because the South Asian family is perceived to constitute its own self-sustaining 'elderscape' (Katz 2009) which inflects assessments of needs of these older women as 'un-needy'.

Research on ageing, gender and personhood in South Asia has shown how there is no singular model of personhood in India. Sarah Lamb (1997) contests the dichotomized view wherein the West represents the individual person and East the relational bounded self. Her research shows that what are often taken as mutually exclusive values, such as relationality and individuality, may actually interpenetrate within the same culture in unique and complex ways. Her ethnographic work with widows in Bengal revealed how personhood through the life course shifted and the focus moved from moving away from tightening of emotional ties to taking them apart (Ibid). The lesson that one derives from this work for the purposes of this study is that there is not one model of understanding South Asian gendered subjectivity. Events during one's life course - marriage, parenthood and widowhood - have an impact on how these bonds are negotiated. Research by Brijnath (2013) has shown how care within the home is the preferred model of elder care and how ideas of 'seva' (voluntary service), reciprocity, duty and love exert strong influence on the negative perception of institutional care. While international bodies like the World Bank and United Nations take elder care beyond the family as a sign of 'progress' and 'development' and as a key element of transition to be becoming a developed nation, Lamb's (2013b) further work shows that this transition is not 'natural' and carries different meanings across cultural, politico-economic and historical contexts. She advocates creative combinations of family and extra-family practices that accommodate societal transformations that are brought on by urbanisation and globalisation.

Lamb's analysis of shifting personhood in a transnational context is useful here for our purposes to move beyond the culturalist understandings of gender and personhood of older South Asian women. Research on transnational families has shown how the institutional context in which transnational families operate plays a major role in hindering or facilitating the maintenance of family solidarity across borders. Some studies have highlighted the ways in which care-giving for older populations has evolved in South Asia as well as in its diaspora context of the UK for the ways in which the South Asian family as a support network is reshaping inter-generational and intra-generational relationships (Burholt 2010; Victor 2012). While these studies have honed in on the psychological aspects of loneliness as indicators of such shifts within the South Asian family's approach towards ageing, we focus on how these shifts are not merely framed by subjectivities around ageing, but also how state and social service discourses are part of this shaping of how South Asian women elders position themselves and their needs.

Older South Asian women's positionality as the nucleus of the family unit is not merely unaccounted for, but is misrepresented within the 'looking after their own' construction (Katbamna et. al. 2004). On the one hand, they are understood as a group with specific needs in 
This is the version of the article accepted for publication in South Asian Diaspora published by Taylor \& Francis online on 16 June 2016 available at: http://dx.doi.org/10.1080/19438192.2017.1339381

Accepted version downloaded from SOAS Research Online: http://eprints.soas.ac.uk/24283/

terms of linguistic and cultural issues, while, on the other hand, their roles within the functioning of the family unit in looking after children and grandchildren, cooking, and in providing emotional as well as economic support are a core feature of how many families sustain themselves across generations. Our exploration looks at how the experience of ageing among older South Asian women is incomprehensible when culturalist notions are employed in making assessments of needs. We argue that unspoken, subverted, or inverted ways of expressing needs by the older women make this a further challenge when assessments and reports are based on formal note-taking and assessments based on facts. Through the ethnography and focus groups conducted in this study, it became clear that women were expressing their needs using one set of communication of indirect speech on the one hand and, on the other hand, being assessed through formal, note-taking measurements unable to penetrate these women's subjectivity and positionality because of the direct speech methods employed. We therefore became attentive to how women reflected upon their everyday lives through 'speech practices' used by women in negotiating their worlds in terms of power, agency, and the family (Narayan 2003). Rather than merely looking at direct speech for its meanings, our methodological attentiveness to 'speech practices' pointed us towards the textures of gendered lives and negotiations which revealed a picture far more complex than the scope of this article. However, our exploration looks at how this is an embodied cultural and gendered sphere, which remains incomprehensible when culturalist notions are employed.

\section{Neoliberalism and 'Care in the Community'}

'Care in the community' ('Domiciled Care' or 'Community Care') is the British policy on the deinstitutionalisation of care for mentally or physically disabled people in their homes instead of in institutional locations such as specialist units or care homes. The idea had been debated for decades until 1983 when Margaret Thatcher's government highlighted the Audit Commission's report Making a Reality of Community Care as a British policy recommendation. The policy on Care in the Community was founded on the premise that the care for older people with disabilities would be a joint responsibility for health and social care professionals and family carers supported by people within their social network. The Care in the Community policy agenda accompanied the cuts to frontline services most notably after 2010 in the UK due to the austerity measures introduced immediately after the election of the Conservative/Liberal Democrat Coalition government in 2010. By 2014-15, a total of $£ 14.9$ billion worth of cuts were made to benefits, tax credits, pay and pensions, with 75 per cent of this taken from women (House of Commons Library, 2012). 'Lone parents' have been significantly affected, 90 per cent of whom are women. For pensioners the projected loss has been in terms of the impact on social care services. It was estimated that these services would be cut by $7 \%$ over four years. The second largest group of women to be affected after single mothers were women pensioners (Ginn 2013). However, the impact of austerity on ethnic minority communities has to date not been systematically assessed.

There were five major changes introduced under the Care in the Community policy framework: 1) Eligibility: a single framework for all services; 2) Community care assessment: a duty on local authorities; 3) Statutory principles: the need for clear interpretation; 4) Carers' assessments: a duty to assess all carers; and 5) Safeguarding adults: a duty to investigate. These changes meant a significant shift, unlike the Children Act of 1989 and the Mental Capacity Act of 2005, the new community care legislation did not contain a concept of fundamental principles. Rather, the principles outlined a number of sets of guidelines and other supporting 
This is the version of the article accepted for publication in South Asian Diaspora published by Taylor \& Francis online on 16 June 2016 available at: http://dx.doi.org/10.1080/19438192.2017.1339381

Accepted version downloaded from SOAS Research Online: http://eprints.soas.ac.uk/24283/

documents, which were meant to offer guidance for interpretation by the representative of local authority (Spencer-Lane 2010). The Dilnot Commission report was then subsequently published which made several recommendations, which became the basis for the Care in the Community programme, which was subsequently chalked out. These shifts marked a dramatic neoliberal turn within social care for the ways in which the Care in the Community programme outlined a new formula for assessing eligibility and needs, offsetting state responsibility for direct provision, and not using a language of entitlements or fundamental principles. Instead, a legislative framework of criteria and duties of responsibility and budget spending between councils/local authorities and central bodies such as the Department of Health resulted in the combining of three pieces of legislation: The NHS and Community Care Act 1990, the Chronically Sick and Disabled Persons Act 1970 and the Disabled Persons Act (Services, Consultation and Representation) Act 1986. The new single Care in the Community policy framework was a landmark shift in how social care would be conceived and subsequently delivered.

A series of research papers published by the Joseph Rowntree Foundation reveal how England is 'woefully' unprepared for an ageing population and that most of the services in the UK were geared towards a population that retired and died afterwards. According to a report from the Association of Directors of Adult Social Services, there is expected to be a $50 \%$ increase between 2010 and 2030 in the population of people aged 65 or older and a doubling of people aged 85 or older (Kennedy 2013). Another study showed how most of the care (either routine or occasional) happens informally in everyday relations with family, neighbours and volunteers and how care and support is a deeply emotional issue (Haslewood 2013). It also highlighted how officially pleas are being made by the Ministry of Health and Social care play their part in reducing care burden. But the research showed as people aged, their social networks were shrinking and were not always available to meet the growing demands. The review of evidence warns against viewing informal relationships as additional resources to be 'tapped into' when other sources become scarce (Ibid).

Other research has shown that older migrants experience a double-jeopardy of marginalisation where two social positions of ageing and migration intersect (Warnes et.al 2004; Torres 2006). Ahmed (2010) in her analysis states that there is a historical legacy of not catering for the needs of older migrants and a lack of knowledge of, or attention to, what their needs are. The institutions deemed responsible to provide care are often ill-equipped or designed to do the same. The welfare state, however, is not neutral and operates within the context of wider social, cultural and ideological structures (Hudson 2013). Indeed, it was 'New Labour' before the abovementioned 2010 reforms which had introduced the personalisation agenda with the aim of supposedly providing more independence and control to care.

There has been a shift from the older population being a care user to a care purchaser with the introduction of brokering in care (Comas Herrera et. al. 2010 in Ahmed). This agenda also assumes that all older people understand the changing care structures and are able to co-ordinate with services to work out their complex care needs. None of the women we interviewed were 'in the know' of these complex changes taking place in the care world. They looked at the women's centre as the nodal point that would make that link and help them co-ordinate care. Ahmed goes on to highlight how the publication of another document in 2010 'A vision for Adult Social Care: Capable Communities and Active Citizens (DOH 2010) furthers this brokering agenda 
This is the version of the article accepted for publication in South Asian Diaspora published by Taylor \& Francis online on 16 June 2016 available at: http://dx.doi.org/10.1080/19438192.2017.1339381

Accepted version downloaded from SOAS Research Online: http://eprints.soas.ac.uk/24283/

further in the name of giving the older population independence. She also mentions how the shift in language from 'health care' to 'social care' is also a means of shifting responsibility onto the individual. Life course attributes like time of migration, gender, country of origin, and place of residence are identified as attributes that impact their needs. Also the South Asian population is a diverse group with complex socio-historical dynamics stemming from routes of settlement, class, gender relations, and contexts in home countries.

The national eligibility criteria maintain a threshold for qualifying for care support. The local authority, not the National Health Service (NHS), is required to provide anyone who meets this eligibility threshold with the appropriate care package. ${ }^{1}$ In addition to being able to have their basic needs met on a daily basis, financial assessments further identify entitlements to welfare provision based on savings and assets which are audited by social workers alongside physical and mental health needs assessments. Thus, the needs assessments which are carried out by social workers on behalf of the local authority have guidelines by which they must be able to show that the threshold has been reached in order to justify the appropriate care requirements. The South Asian family, when put under the scrutiny of assessment and audit is, at least in principle, built on a patrilineal base of co-residence and care of elders by sons and their spouses (Sokolovsky 2009). However, as our study shows, the family as a lived experience and function of society, not an ideal, makes these assumptions problematic when being incorporated into needs assessments by agencies.

This era of cuts is significant in terms of how social and healthcare services continue to utilise this imagined myth of the South Asian family as a tool in their judgments and assessments of the needs of older South Asian women. This myth is largely framed by the hallmark of the South Asian woman as an upholder of family values and by virtue of that an epitome of selflessness and sacrifice, a requirement for the replacement of welfare provision under austerity. The Care in the Community model also presumes that such social networks are common features of all communities in contemporary Britain. An analysis of carers' accounts suggests that for a variety of reasons, the main carer, irrespective of gender, has had limited support both in nuclear and extended families. In addition, societal attitudes towards disability and the fear of obligation prevented the seeking and accepting of help from wider social networks. We argue here that these assumptions about the functions of the extended family about their willingness and ability to provide care are problematic (Katbamna et.al. 2004). Further, we wish to problematise the concept of kinship as a supportive structure for these South Asian women in the diaspora for whom home, family, community and welfare are all concepts which are not static and which are fraught with concerns of what 'care' means in the lifecycle for older women as carer and care recipients

\section{Calling on Kinship}

Marilyn Strathern (1981) highlighted how the social constructions of gender 'norms' are constantly being utilised in evoking gender imagery, "a symbolic mechanism whereby 'collective' and 'personal' interests are made to seem to be of different orders". The selfsacrificing self-construction by the older South Asian women in this study point towards this gender imagery in which the collective and personal are being articulated by older women through mediums which fail to be deciphered by the care system. We challenge this perception of South Asian kinship as an inherently caring unit through two problematisations. The first 
This is the version of the article accepted for publication in South Asian Diaspora published by Taylor \& Francis online on 16 June 2016 available at: http://dx.doi.org/10.1080/19438192.2017.1339381

Accepted version downloaded from SOAS Research Online: http://eprints.soas.ac.uk/24283/

problematisation draws on Ranajit Guha's depiction of 'the rounded unitary world of kinship' in which the household is viewed as a unit which provides collective social functions in which needs are fulfilled and met its members. This unitary world of kinship provides the basis of the myth of culturally informed socialisation in which elders are cared for by the family unit through moral obligation and the ties and bonds of kinship. The second problematisation is of perceptions of the South Asian family as a strong unit of social organisation without an understanding of how patriarchal structures place women in positions in which indirect rather than direct articulations of needs are voiced. Illustrating this, Kirin Narayan (2003) and Ann Gold (1992) point to the seemingly confrontational lyrics of north Indian women's folk songs in which gender 'banter' is prevalent in subverting and inverting hierarchies of power and kinship. Thus, direct speech is often avoided by women in order to not appear to be outside of the unitary world of the collective unit. However, as Raheja (2003: 174) insightfully poses, there are 'multiple and shifting and negotiated and sometimes ambiguous solidarities that women may propose as they encounter that seemingly rounded unitary world'. Women's speech practices are a key function in how power is negotiated through processes of subverting and inverting. This banter which signifies knowing subjectivities of how women are perceived as well as how they can negotiate and capitalise upon these perceptions, are the underlying script of how kinship and caring are articulated by women. Instead of making direct demands around needs to professionals or family, older women express their needs through indirect and subverted modes of communication which, we argue, take them out of the spotlight of being 'needy.' In this light, the notion of the family and kinship as key to the delivery of care to children and the older population is not merely a social and cultural one, but also an economic one.

The existing literature on social support networks in minority ethnic communities is based largely on the nature of kinship ties between and within generations and focuses on issues such as who in the kinship network is most likely to be approached for help and levels of satisfaction with the support that is available and provided. For instance, the findings of Phillipson et al. (1998) revealed that the social support networks of Indian and Bangladeshi elders were mainly located within multigenerational households, and children and spouses were the primary source of support for older people. Stopes-Roe and Cochrane (1990) also reported that the presence of an extended kinship network did not necessarily signify a larger pool of potential support for members of the household. Centrality of kinship in studying South Asian lives has meant that the home has been the focus of the study. However, other studies have also shown that networks beyond kinship have been used by ethnic minorities in relation to Pakistani entrepreneurship and for marriage arrangements (Werbner and Shaw in Mand 2006).

The reluctance of South Asians to take up service provision in proportion to their needs has also been noted to be in part attributed to the extensive reach of day care centres targeted at these communities and also due to the establishment of networks of care of elders within South Asian families. Jewson et al (2003) found what they called a 'respite iceberg' in South Asian communities in Leicester where there was a 'large and unfulfilled need for respite care hidden beneath the surface of on-going family support for elders' (p. 5). Research conducted with South Asian women elders in a community centre in East London brought out the importance of social and neighbourhood networks and friendships in light of the changing family structures and occupational mobility. The community centre emerged as a site where 'dosti' (friendship) emerged as an important variable in the negotiation of happiness of these women (Mand 2006). Earlier research had suggested occupational mobility, growing preference for nuclear household 
This is the version of the article accepted for publication in South Asian Diaspora published by Taylor \& Francis online on 16 June 2016 available at: http://dx.doi.org/10.1080/19438192.2017.1339381

Accepted version downloaded from SOAS Research Online: http://eprints.soas.ac.uk/24283/

arrangements, housing problems and the fragmentation of family networks as the cause of weakening of kinship networks (Stopes-Roe \& Cochrane 1990, Blakemore and Boneham 1994, Elliot 1996, Modood et al. 1997).

The mechanisation of care further alienates South Asian women. The complexities around women's positionality within kinship networks and how they position themselves within 'the family', in particular, call for an analysis of older women's reflections on their current circumstances and reflections as well as on the lifecycle itself. This group of South Asian women elders provide insights not only into the subjectivity of ageing but also of how the women negotiate using voice and agency through the maze of gender, generation, age and power not only at home but also in how they reflected upon their lives in the company of friends and acquaintances.

\section{The Study}

The findings of this study have been drawn from fieldwork conducted in the West Midlands city of Birmingham. Birmingham, which has an estimated population of 1.1 million population, is also the centre of the region of the West Midlands which has a 5.5 million population and a high concentration of South Asian communities. According to the 2011 Census, the population breakdown shows a 4.1\% Pakistani, 3.9\% Indian, and 0.9\% Bangladeshi demographic presence in the region. The study is based on in-depth fieldwork conducted between 2012 and 2014 at a women's centre specifically aimed at South Asian women ${ }^{2}$ in this community..Focus group discussions were conducted at The Centre at a regular monthly older women's luncheon club.

The luncheon club was set up as a means of providing older women with an outlet to meet with women of their generation with whom they can share experiences and to socialise. With all women attending the group in their $60 \mathrm{~s}, 70 \mathrm{~s}$ and $80 \mathrm{~s}$, it was identified as an appropriate means by which to ascertain older South Asian women's collective perceptions of their needs and to elicit their views and individual experiences of the functions of family and their roles within it. Women in the focus group were not known to each other outside of the Centre, and this further enabled what the authors perceived as relatively unguarded and open responses to the issues being discussed without fear of their comments being reflected back to their families or social networks. Both the authors are trained social scientists who have worked on issues on gender and subjectivity both in South Asia and its diaspora.

Four focus groups in total were conducted with eighteen women who were predominantly Punjabi (Sikh and Hindu) as well as Bengali (Muslim) and Gujarati (Hindu), reflecting the demographic composition of the local population where the Centre is located. Both authors conducted the focus group sessions which lasted two hours each in Hindi and Punjabi. Each of the focus group sessions were conducted with approval from the management and participants and were recorded with permission of the participants. The focus group discussions were then translated and transcribed from Hindi and Punjabi to English. The first focus group centred on the topics of stress and emotional health issues, and the second focus group addressed sources of support and coping strategies focused on their perceptions of personal care needs. The third and fourth focus groups were conducted specifically as part of legal and financial advice information 
This is the version of the article accepted for publication in South Asian Diaspora published by Taylor \& Francis online on 16 June 2016 available at: http://dx.doi.org/10.1080/19438192.2017.1339381

Accepted version downloaded from SOAS Research Online: http://eprints.soas.ac.uk/24283/

sessions with invited outside speakers. All sessions were directed towards women's senses of self and subjectivity. The core causes of stress and anxiety identified by the women were: bereavement; children not being 'settled'; unhappiness at home; loneliness and isolation; and insecurity. Our analysis is shaped by our coding of the focus group sessions and through our understanding of inverted speech practices.

\section{Culture, Entangled Selves and Wellbeing}

Bereavement of partners and worries about unmarried children dominated the discussion about happiness and unhappiness. Spells of what were defined as 'depression' by the women were tied into bereavement within the family, in how they were reflected by the women. There were women within the group that had been widowed who spoke at length about the mental and emotional challenges posed by widowhood.

As one widow who was a regular visitor of the Centre reflects:

R2: My weakness or negative things that have happened, like loss of family members, is difficult to cope with. Coping with that I find difficult. Now it has been fifteen/sixteen months since my husband's death so I have not gotten out of bereavement for one year, and I keep myself busy, go to the gym, and try to not get depressed.. And depression being what it is, when it starts it's very hard to get out of. [10.33]

Author 2: It becomes like a cycle?

R2: Yes, like a cycle, so I got depression after my mother's death. Six months I stayed down but I pulled myself together and made myself well. That was thirteen years ago, and I don't want to feel like that again, so I keep myself busy, so this is about me.

R7: ...in life pains and ease ['dukh-sukh'] are always happening. I never really felt it consciously but there is one pain that I did particularly feel because it has been two-three years since my husband has been gone. He died. He used to walk around and just be so much fun: sometimes do this, sometimes do that. I was so happy when he came into my life, but this pain which came was so big and it has no relief. I don't need to say anything else, nor can I.

Loss of a partner in accounts of many of these women altered their relationship with life. They were compelled to take on responsibilities that they shared with their partners and renegotiate their relationships with the state, community and family. These alterations and the loss of companionship especially in a context where children lived away or separately for work implied that they had to get used to living alone and find a sense of self.

The second issue that affected their sense of wellbeing was seeing their children settled. On pushing them further on what being 'settled' meant we were told:

Author 1: What is the meaning of 'settle'? When they get married? 
This is the version of the article accepted for publication in South Asian Diaspora published by Taylor \& Francis online on 16 June 2016 available at: http://dx.doi.org/10.1080/19438192.2017.1339381

Accepted version downloaded from SOAS Research Online: http://eprints.soas.ac.uk/24283/

R1: When they settle in their own place.

Author 1: They work?

R1: They do work.

Author 1: Just not marriage?

R1: They just don't get married. That's all that settling down is; that's all a mother and father want.

Giving, caring and fulfilling their responsibilities as wives, mothers, and grandmothers came above everything else in the first focus group that was conducted. Giving was not just limited to the family. A few also spoke about giving to society and the community in terms of active social work and making themselves useful within the extended community.

Author 2: Hmm, fighting with it shattered you?

R5: Yes, but I have pulled through and what makes me happy, is my two children. If they are happy, I feel happy. My happiness is so deeply linked and connected with them. If they are doing well and they are happy, I am very happy. If they get upset, that upsets me automatically. Otherwise I'm basically an independent person but this aspect of my life is that I am not independent of my children. Children, family back home... these things are very connected to my personal happiness.

Evidence above shows how most of these women derived their sense of being through emotional entanglements and fulfilling culturally prescribed roles. As researchers, we found it challenging to get the women to speak about their own emotional and physical needs. Their sense of being was tied into the wellbeing of the family. The formal setting of the community centre, the presence of women from management, and our presence as two researchers of South Asian background might have brought out responses that were culturally prescribed. Our intention was not to view them as disentangled eastern bodies living in the west, but to make them speak about their lives as hybrid individuals who are living in one place, but spanning an array of cultural and spatial reference points - negotiating emotional bonds and everyday needs in a new context called 'home' in Britain. ${ }^{3}$

The analysis of the transcripts further showed how ageing creates a sense of isolation and loneliness, even when children are married and grandchildren are living in proximity. The generational expectations by elders to be looked after in old age by their children and grandchildren to succeed in their own ambitions were identified as a key source of anxiety and often disappointment by the women. The women expressed not wanting to be a burden upon younger generations and yet held desires to be valued and cared for by their children. For many of the women, being dependent upon children because of lack of English or for transportation gave them a sense of helplessness and dependency. Despite the fact that the family was central to their happiness, the researchers picked up on a sense of loneliness that was not always articulated directly. One or two off-hand comments were made about coping on their own during 
This is the version of the article accepted for publication in South Asian Diaspora published by Taylor \& Francis online on 16 June 2016 available at: http://dx.doi.org/10.1080/19438192.2017.1339381

Accepted version downloaded from SOAS Research Online: http://eprints.soas.ac.uk/24283/

the second focus group when we encouraged them to speak about themselves as individuals. Their needs, crucial events during their life course, and the place of religion in their lives to cope emerged in the focus group conversation which brought out some of the unarticulated needs:

RESPONDENT 5: And my other son that lives here is different. What can I do? If I phone him, he says Mum I haven't got time. Then do you ring again? If they haven't got time then what are going to get out of telling them.

RESPONDENT 5: What our children do for us, our daughters-in-law and sons, whether it is a little or a lot... in the future with Grandsons and Granddaughters, there is no telling.

RESPONDENT 1: Why? Why is there no telling?

RESPONDENT 5: Because they say 'what are the centres made for? For the elderly!'

Despite the 'settling down' of children identified as a main anxiety among the women, their expressions of their lives were centred on the happiness of their families and children, with a majority of them admitting to coping on their own. Changing family structure (joint to nuclear families), loss of partners, migration for work and busy professional working lives were cited as a few reasons why the family was absent when it came to providing care. Unmet needs and everyday suffering, as we found, underlie the hegemony of the South Asian family narrative. Upon further probing, we were told by both the women and the Centre staff that they require help with practical tasks in their daily lives, and they were not sure whom they could turn to. Their families expected them to ask the Centre for help. The Centre's priorities were dictated by funding and, beyond providing a social space and running English and computer classes, there was very little that the Centre did in this respect.

\section{Expectations of Care: Family, Community or State?}

The delivery and expectations of 'care' have become increasingly blurred under the Care in the Community agenda. Where the state, through its various agencies once operated through a comprehensive welfare approach to care, this has now become, as we have earlier highlighted, a configuration of needs thresholds, assessments, and a move towards payment for services. By positioning this group of older South Asian women within this neoliberal framing of care, we found that the cultural perceptions of the family and South Asian kinship as inherently 'caring' obscures the underlying needs of older people who appear as the nucleus of the household. While most women in our study spoke about coping on their own or through support from immediate family and friends, some of them admitted that coming to the Centre was comforting as they realised that there were women who were in a similar position to them. The Centre was the main hub of support and the women looked forward to the socialisation it provided. We were told 'jee halkaa ho jaataa/jaandaa' (we feel a sense of lightness). With respect to their interactions with public services, some women specifically mentioned the word 'depression'.

Author 2: In this sadness and happiness, have you ever been to the NHS or got medicine. 
This is the version of the article accepted for publication in South Asian Diaspora published by Taylor \& Francis online on 16 June 2016 available at: http://dx.doi.org/10.1080/19438192.2017.1339381

Accepted version downloaded from SOAS Research Online: http://eprints.soas.ac.uk/24283/

R1: No, I never. What we do is we come here, we get company, share about our lives and our mind gets a bit freer, and that's it.

Some of them had been to the GP for help when they had stressful periods in their lives. No members from the group had been institutionalised nor had any formal diagnosis of any mental illness. A few of them had been on anti-depressants and found them useful in getting through stressful life events.

Author 2: You took help from the medical system. Do you mind sharing what help you took from the medical system?

R5: Well I felt very low and shattered. I went to my GP and discussed it with him, and then he put me on some medicine which helped me.

Author 2: And it helped you cope?

R5: Yes, I think...

While help through the GP for medical and non-medical problems was something that some of them were comfortable seeing, it was mediated by class and education. Women who were educated and had professional working lives found it easier to seek professional help. The uneducated women coped by confiding in families and close friends. This was, in part, due not only to education but also fluency in English, which gave confidence to many of the women in making appointments. Not all felt they could access family and friends when they needed them. Concerns were raised about rumours and gossip-mongering in the community. In light of medical help being minimal and the family often being the source or trigger of distress, the women highlighted 'getting out' activities as essential to their well-being. They identified places they visit as part of their coping strategies such as the Centre. Regularly going to the Gurdwara, Mandir or Mosque was also a core activity of many of the women's weekly, often daily, routines.

RESPONDENT 4: There's one on [X road], there is another one a bit further on [Y Road], and one more. [X Road] is near. There are lots of Gurdwaras. But [X Road] is near, so I am used to it. If I don't feel like doing work at home, then I go to the Gurdwara and remember/visit God (darshan).

Submission to God was advocated as a solution by a few women within the group who had struggled with long-term physical health problems and stress in the home environment.

RESPONDENT 5: If I keep saying it and making people listen to me always, the one who always has to listen also gets annoyed with it. I don't want to trouble anyone. I have God. I speak with him. Whatever troubles I have, I tell him about my troubles. ...like, 'God, this is the problem, how shall I...'? 
This is the version of the article accepted for publication in South Asian Diaspora published by Taylor \& Francis online on 16 June 2016 available at: http://dx.doi.org/10.1080/19438192.2017.1339381

Accepted version downloaded from SOAS Research Online: http://eprints.soas.ac.uk/24283/

RESPONDENT 5: But if we keep trust in one path, then God does listen to us. We always find a way. I have seen these things quite a few times. It has been a while since I have had Arthritis. It has been thirty, thirty-five years. Miracles have been delivered.

Religious places of worship, however, are social institutions and sites of community, which are not removed from the family and social networks, especially for elders. Being able to share one's concerns or worries was not a part of the impetus to visit religious places due to the lack of discretion and the inter-linkages between family and community present there. In some cases, speaking to the GP was viewed as an alternative to speaking within the family or with friends, which was viewed cynically as potentially providing gossip for others. The fear of 'washing one's dirty linen in public' was expressed collectively. Most of the women agreed that personal struggles and worries could not be shared with relatives when their sense of fulfilment was through giving, not taking. However, several women identified that they had one person who they could confide in with whom they had a sense of trust.

As expressed by the women in our study, the medical and social care system, family and kinship networks, the Centre with its friendship circles, and religious institutions were all on a continuum, and these women picked and chose across the spectrum according to what worked for them. The fact that the family was not able to meet all of their needs meant that they had to seek help on their own, and, in many cases, could not always express their needs to the social workers and doctors coming to see them. The Centre provided a space for sharing, and friendships here became an extension of the kinship network as pointed out by similar research in London (Mand 2006). But there were limitations to what the Centre could provide and most narratives had this underlying sense of suffering (which came from unfulfilled needs) and coping on their own that was not picked up by the families, the services and the Centre. Indeed, many of those of this generation of South Asian elders have lived through decades of welfare provision and would no doubt have been reflecting on the changes that have taken place as a result of the cuts to social services, including to the Centre, that they are now experiencing as elders. The coming together at the Centre allowed them to engage socially, share meals, and learns skills.

It was very evident that some of these women were struggling physically with bodily aches and pains but also had emotional, material and legal needs that needed practical attention and even intervention. We caught a glimpse of it when they were asked to provide a list of things that they wanted to hear about or made direct suggestions for informative sessions they wanted to have organised at the Centre for them:

As stated by one of the women:

just organising talks will not do. How can you help us? We need more and we don't know where to go for help. We come to the Centre and they say that they can only provide training in computers and help us in English. That is not enough.

\section{Neoliberal Care and the Safety Net of Culture}


This is the version of the article accepted for publication in South Asian Diaspora published by Taylor \& Francis online on 16 June 2016 available at: http://dx.doi.org/10.1080/19438192.2017.1339381

Accepted version downloaded from SOAS Research Online: http://eprints.soas.ac.uk/24283/

It was evident that the state, through its various agencies, was fairly absent from the lives of the women of this study apart from attending to immediate physical needs and for turning to help during periods of distress, which again was mediated by class. Their recollections of entitlements and welfare were reminiscent of the period marked by what Harvey (2006) calls the social democratic European state's Keynesian compromise which had tolerated a certain amount of public benefit through redistributive measures such as the welfare state. Thus, their entry point as migrants in post-colonial Britain, whether as wage labour or as reproductive labour, meant that their positionality within the welfare system was one of entitlement through the public rather than the family sphere.

In the neoliberal context of diminishing entitlements to welfare care provision in contemporary Britain, Care in the Community relies upon the household unit to provide the safety net to absorb that which was once delivered by the state. Thus, it is only those who are deemed most 'needy' and who meet the increasingly stringent economic, social and physical criteria who are able to avail comprehensive provision. Women who had high physical needs, like a woman suffering from arthritis or someone who had undergone hip or knee replacements, had social workers visiting them, but were mostly on their own. Their families expected the Centre to fill in the void that was left by the state, yet the Centre was bound by its priorities to secure funding in order to sustain itself and was also ill-equipped to meet needs beyond drop-in information sessions and basic social sessions as it did not employ trained personnel who could deliver more than these social needs. Indeed, part of the neoliberal effects on community organisations is the altered landscape which has been generated by cuts to the voluntary sector such as the Centre focused upon in this study. There was a significant gap between the state's provisions and expectations of these older women and their families

The extended/joint family operates as an imaginary and an ideal. Just as social workers utilise their cultural understandings of the family when making needs assessments in order to make judgments around whether or to what extent state provision of care is necessary, the extended family also functions as an ideal for older South Asian women in our study for whom 'living together' or having at least two generations living under the same roof represents an ideal. However, as culture is inflected by economic and material relations, the extended family as well as the ideal of the patriarchal household have been subject to tremendous change. The conversations that took place around the family during the legal advice session, highlighted the sense of insecurity which many of these women felt. They reflected on their concerns about their personal and financial insecurities stemming from what they identified as the nuclearisation of the family- something shared by all of these women. A legal advice session, requested by the women after our first two focus groups, was arranged by the Centre and a family law solicitor gave a presentation on basic information to the women.

R6: Tell us something about that thing you mentioned? How can we decide who we give what to?

Solicitor: You mean about having a will?

R6: Yes, but also writing it before the marriage and then afterwards too... you know we can't just give it all away. We have to have some power left in our hands. 
The idea of having a will, in a cultural context in which women do not customarily inherit property, was a noticeable area of enquiry by these women. During the legal advice session, we became alerted to the financial concerns of these women, and we became aware that the notion of 'care' and of ageing, which we had pursued in the first two focus groups, placed the questions in a circumscribed conversation around health, the body, wellbeing, and happiness. Underlying many of the concerns here, it became apparent in the legal session, were not only tensions with younger generations around their lack of 'care' for their elders but tensions around the insecurity that these women felt in old age in terms of assets, control and authority within the family unit. They wanted to know what options were available to them and what their legal, not kinship, entitlements were in relation to their husbands, children, children's spouses, and grandchildren. Direct questions were posed around inheritance and what the meanings and differences were between pre-nuptial and post-nuptial agreements in relation to their sons' marital arrangements. Several women made it clear that they would only follow conventions around property being passed onto sons, while others vehemently stated that they would leave any assets to both daughters and sons, and even grandchildren in challenging the norms of patrimony at the base of the patriarchal joint/extended family. While this was somewhat of a tangent from our initial research questions, the financial and economic base of the family in this era of neoliberal pressures on the family and household highlights this as an important area, though not possible to be explored within the limited scope of this research.

\section{Conclusion}

This article has examined how South Asian women elders are experiencing the neoliberal turn implicit in the Care in the Community agenda. The neoliberal social care system as it is evolving utilises this imagined myth of the South Asian family as a tool in its judgments and assessments of the needs of older South Asian women. Conceptions and assumptions about how older people are cared for by South Asian families and communities, despite being problematic, continue to be systematically utilised. While one of our aims was to dispel the myth of the South Asian family, we have also attempted to highlight an identifiable gap between women's expectations of the family to provide fulfilment and happiness and their disappointment when these expectations are not met. Their sense of disappointment and isolation even within the family walls highlights how perceptions of well-being from within the South Asian community are viewed rather differently to how social and health services assessments perceive those who are placed at its apex. These older South Asian women, rather than having passively unintelligible needs, are shaping an evolving 'elderscape' of care and community which is both absorbing the cuts to care provision once provided by the welfare system as well as highlighting emerging points of insecurity and coping mechanisms.

Guha's (1987) interrogation of the 'rounded unitary world of kinship' provides a clarifying lens through which to understand both the agency and positionality of these older women within social relations and structures of the family, community and the state. While perceptions, assessments and assumptions about these women percolate across family, community, and agencies, our fieldwork research explicates the ways in which speech practices, drawing on the work of Narayan (2003) and Gold (1992), reveal women's expressed and concealed needs as 
This is the version of the article accepted for publication in South Asian Diaspora published by Taylor \& Francis online on 16 June 2016 available at: http://dx.doi.org/10.1080/19438192.2017.1339381

Accepted version downloaded from SOAS Research Online: http://eprints.soas.ac.uk/24283/

articulated in direct and indirect speech. We extend the conceptual and methodological use of speech practices to the notion of care in order to understand how the unitary world of kinship is negotiated. Indirect and direct speech are used within an underlying script of how negotiations around kinship, needs, and caring are articulated by women. We found that instead of making direct demands around needs to professionals or even family members, older women express their needs through indirect and subverted modes of communication which do not get picked up by the increasingly mechanical and bureaucratic needs assessment system.

Our findings align with Sarah Lamb's contributions to the field of ageing, gender and personhood in South Asia and the diaspora in questioning the dichotomized model of individual personhood in the 'West' and bounded relational selves in the 'East.' This model is at the core of the needs criteria assessments which are hinged on the family unit to undertake responsibilities for care at home and in the community, and the older South Asian women in our study are at the cusp of this model. While Lamb (2013b) advocates for innovative combinations of family and extra-family measures for care, we argue that this cannot be done without a sharp attentiveness to the ideological underpinnings of the neoliberal care model. Given that this model of care in the community fundamentally relies on the family and kinship to uphold the system in the context of rescinding public care provision, the expectations and articulations of the South Asian women in our study highlight how expectations by both family members and their carers are often unfulfilled and unaccounted for in the ways that needs are assessed and addressed by family and state and other agencies.

The myth of the family is largely hinged on the hallmark of the South Asian woman as an upholder of family values. The women in our study simultaneously embodied the archetypal South Asian family's caring functions while also, through subverted/indirect speech practices, also reflecting the gaps, silences and unmet needs which the neoliberal model is failing to identify and address. Thus, the very women who find fulfilment and happiness from family wellbeing and prosperity are absorbing the strains of the withdrawal of state provision, generational shifts around the culture of caring in the family, and expectations of women's roles as they move through the life course and navigate the shifting terrain of 'care'. 
This is the version of the article accepted for publication in South Asian Diaspora published by Taylor \& Francis online on 16 June 2016 available at: http://dx.doi.org/10.1080/19438192.2017.1339381

Accepted version downloaded from SOAS Research Online: http://eprints.soas.ac.uk/24283/

\section{Bibliography}

Audit Commission for Local Authorities in England and Wales (1983) Making a Reality of Community Care.

Blakemore K. and Boneham M. (1994) Age, Race and Ethnicity Open University Press, Buckingham.

Brijnath, B. (2012) Why does Institutionalised Care not appeal to Indian Families? Legislative and Social answers from Urban India. Ageing and Society. 32. $697-717$.

Burholt, V. (2010) 'Caregiving and carereceiving relationships of older South Asians: Functional exchange and emotional closeness,' Geropsych: the journal of gerontopsychology and geriatric psychiatry, Vol. 23, Issue 4, pp. 215-225.

Ginn, J. (2013). Austerity and Inequality: Exploring the Impact of Cuts in the UK by Gender and Age. Research on Ageing and Social Policy. Vol 1. No. 1. 28-55.

Gold, A. (1992) A Carnival of Parting. Berkeley: University of California Press.

Guha, R. (1987) 'Chandra's Death' in R. Guha (ed.) Subaltern Studies V: Writings on South Asian History and Society. pp. 135-165.

Harvey, D. (2006) Spaces of Global Capitalism, Verso: London.

Haslewood, I. (2013) 'We can't assume informal support will plug the care funding gap,' Joseph Rowntree Foundation, https://www.jrf.org.uk/blog/we-can't-assume-informal-support-will-plugcare-funding-gap, Accessed 21 May 2017.

Jewson, N., S. Jeffers, and V.S. Kalra (2003) 'In Our Blood: Respite Care, Family Care, and Asian Communities in Leicester.' University of Leicester.

Katbamna et.al. 2004. Do they look after their own? Informal Support for South Asian Carers.

Katz, S. (2009) 'Spaces of Age, Snowbirds and the Gerontology of Mobility: The Elderscapes of Charlotte County Florida' in J. Sokolovsky (ed.) The Cultural Context of Ageing, Greenwood Publishing: Westport, pp. 463-486.

Kennedy, J. (2013) 'We need a plan to care for our ageing society,' Joseph Rowntree Foundation, https://www.jrf.org.uk/blog/we-need-plan-care-our-ageing-society), Accessed 21 May 2017.

Lamb, S. (1997) The Making and Unmaking of Persons: Notes on Gender and Ageing in North India. Ethos. 25 (3): 279 -302. 
This is the version of the article accepted for publication in South Asian Diaspora published by Taylor \& Francis online on 16 June 2016 available at: http://dx.doi.org/10.1080/19438192.2017.1339381

Accepted version downloaded from SOAS Research Online: http://eprints.soas.ac.uk/24283/

. 2002. 'Intimacy in a Transnational Era: The Remaking of Ageing among Indian

Americans'. Diaspora. 11:3. 299 -330. 23

2013 a. Personhood, Appropriate Dependence, and the Rise of Eldercare Institutions in India, in: Lynch, C., Danely, J. (Eds.), Transitions and Transformations: Cultural Perspectives on Ageing and the Life Course. Berghahn, New York, pp. 171-187.

2013 b. Independence, Intergenerational Uncertainty and the Ambivalent State: Perceptions of Old Age Security in India. South Asia: Journal of South Asian Studies. Vol. 36. No. $1,65-78$

Mand. K. (2006) 'Social Relations Beyond the Family?' Community, Work and Family. Vol. 9. No.3.309-323.

Modood T., Berthoud R., Lakey J., Nazroo J., Smith P., Virdee S.. \& Belshon S. (1997) Ethnic Minorities in Britain: Diversity and Disadvantage. Policy Studies Institute, London.

Narayan, K. (2003) 'Singing from Separation: Women's Voices in and about Kangra Folksongs' in Gloria G. Raheja (ed.) Songs, Stories, Lives: Gendered Dialogues and Cultural Critique. Kali for Women: New Delhi.

Phillipson C., Bernard M., Phillips J. \& Ogg J. (1998) The family and community life of older people: household composition and social networks in three urban areas. Ageing and Society. 18, 259-289.

Raheja, G. G. (2003) 'Negotiated Solidarities: Gendered Representations of Disruption and Desire in North Indian Oral Traditions and Popular Culture' in Gloria G. Raheja (ed.) Songs, Stories, Lives: Gendered Dialogues and Cultural Critique. Kali for Women: New Delhi.

Sokolovsky, J. (2009) 'Families, Communities and Elderscapes: Transforming Cultural Spaces for Ageing,' in J. Sokolovsky (ed.) The Cultural Context of Ageing, Greenwood Publishing: Westport.

Spencer-Lane, T. (2010) Five Key Reforms to Re-Shape Adult Care Law, Community Care, February 23, 2010, (http://www.communitycare.co.uk/2010/02/23/five-key-reforms-to-re-shapeadult-care-law/) [accessed 25 April 2017.]

Stope-Roe, M. and Chochrane R. (1990) 'Support Networks of Asian and British Families: Comparisons between Ethnicities and between Generations'. Social Behaviour, 5, 71-85.

Strathern, M. (1981) "Self-Interest and the Social Good: Some Implications of Hagen Gender Imagery." Pp. 370-391 in Readings for a History of Anthropological Theory, edited by Paul A. Erickson and Liam Murphy. Toronto: University of Toronto Press.

Torres, S. (2006). Elderly Immigrants in Sweden: Otherness under construction Journal of Ethnic Migration Studies. Vol 32. Issue 8. 
This is the version of the article accepted for publication in South Asian Diaspora published by Taylor \& Francis online on 16 June 2016 available at: http://dx.doi.org/10.1080/19438192.2017.1339381

Accepted version downloaded from SOAS Research Online: http://eprints.soas.ac.uk/24283/

Warnes et.al. (2004), The Diversity and Welfare of Older Immigrants in Britain. Ageing and Society. Vol 24. Issue 3. 307-326.

Victor, C., V. Burholt and W. Martin (2012) 'Intergenerational Relationships and Support Networks of Older South Asians: A comparison of elders living in the UK, India and Bangladesh', Journal of Cross-Cultural Gerontology, Vol. 27, No. 1.

${ }^{1}$ http://www.nhs.uk/conditions/social-care-and-support-guide/Pages/assessment-care-needs.aspx\#eligibility

2 The authors are aware that South Asian Women are not a monolithic category and come from different countries of the sub-continent, have varying community and migration histories, speak different languagesand come from a mixture of rural and urban areas. In this paper they come together as South Asian Women in their experience of marginalisation from services and in their experience of being part of the South Asian diaspora that is located in an inner-city area of a British city.

${ }^{3}$ This point has been made by Lamb (2002:304) in her work with older Indians in American who live in one location, but draw from and negotiate between a milieu of cultural worlds. These worlds are overlapping and allow the elders to negotiate conceptions about how things should be or how things are, exchanges with kin, ties of affection, memories of homeland, sense of national cultural identity, State policies surrounding ageing and modes of death and dying. 